\title{
UTM and D-NET: NASA and JAXA's Collaborative Research on Integrating Small UAS with Disaster Response Efforts
}

\author{
Jeffrey Homola, ${ }^{1}$ Marcus Johnson, ${ }^{2}$ and Parimal Kopardekar ${ }^{3}$ \\ NASA Ames Research Center, Moffett Field, CA, 94035, United States \\ and \\ Adriana Andreeva-Mori, ${ }^{4}$ Daisuke Kubo, ${ }^{5}$ Keiji Kobayashi, ${ }^{6}$ and Yoshinori Okuno ${ }^{7}$ \\ Japan Aerospace Exploration Agency, Mitaka, Tokyo, 181-0015, Japan
}

\begin{abstract}
Natural disasters, such as flooding, wildfire, hurricane, tornadoes, earthquakes and tsunamis, pose challenges in preserving human life and minimizing the damages to a region. During catastrophic events, timely response of disaster relief personnel, an efficient deployment of resources in the recovery effort, and coordinated information sharing amongst different relief agencies can make a substantial difference in responding to those impacted by the disaster. Many relief activities currently utilize both ground personnel and manned airborne assets during different phases of the disaster response. Typically, multiple organizations support relief activities and this often creates logistics coordination challenges between agencies which can result in wasted time or resources. The Japan Aerospace Exploration Agency (JAXA) has been developing an "Integrated aircraft operation system for disaster relief (D-NET)", which assists collection and sharing of disaster information through the integrated operation of aircraft such as helicopters, aircraft, and satellites, for efficient and safe rescue operations by disaster relief aircraft. Due to the advancement in unmanned aircraft systems (UAS) technologies, public safety organizations have started incorporating small UAS (sUAS) as an asset in their disasters response activities. To address the airspace integration challenges of the influx of sUAS in the United States the National Aeronautics and Space Administration (NASA), under the UAS Traffic Management (UTM) project, has been engaged in research to enable large-scale commercial applications of sUAS operating in low altitude airspace. This paper presents the integration of D-NET, which incorporate sUAS in the planning, information sharing, and operation support of disasters response activities, and UTM, which provides airspace management to enable large scale high density operations. The integration of the DNET and UTM systems enables coordination, data sharing, and airspace management to improve the timeliness of the disaster response, enable relief organization to reduce cost and overhead by using UAS assets and still maintain airspace safety during the relief activities.
\end{abstract}

\section{I.Nomenclature}

$D-N E T=$ Integrated Aircraft Operation System for Disaster Relief

$J A X A=$ Japan Aerospace Exploration Agency

sUAS = Small Unmanned Aircraft System

$N A S A=$ National Aeronautics and Space Administration

UAS = Unmanned Aircraft System

UTM = UAS Traffic Management

\section{Introduction}

$\mathrm{T}$ The National Aeronautics and Space Administration (NASA) of the United States and the Japan Aerospace Exploration Agency (JAXA) of Japan have embarked on a collaborative research plan to enable the integration

${ }^{1}$ UTM Integration and Testing Lead, UAS Traffic Management.

${ }^{2}$ Deputy Project Manager, UAS Traffic Management, AIAA Member.

${ }^{3}$ Principal Investigator, UAS Traffic Management, AIAA Associate Fellow.

${ }^{4}$ Researcher, Technology Demonstration Research Unit.

${ }^{5}$ Senior Researcher, Technology Demonstration Research Unit, AIAA Senior Member.

${ }^{6}$ Senior Researcher, Technology Demonstration Research Unit.

${ }^{7}$ Senior Chief Research Engineer, Technology Demonstration Research Unit, AIAA Senior Member. 
of small unmanned aircraft systems (sUAS) in disaster response management efforts. In the United States, NASA has been engaged in research to enable the large-scale commercial application of sUAS in low altitude airspace as part of the UAS Traffic Management (UTM) project. In Japan, JAXA has developed the Integrated Aircraft Operation System for Disaster Relief (D-NET) to manage resource allocation during disaster response operations and to optimize the application of available assets. The goal of this collaborative research effort between NASA and JAXA is to leverage core capabilities that have been developed as part of UTM and integrate them with D-NET in order to provide the ability to deploy and manage sUAS as part of wider disaster response efforts.

In disaster and emergency response situations, the use of manned aircraft assets are often a key component of an effective response strategy. However, low altitude and high-density visual flight rules (VFR) disaster aircraft operations pose a number of considerable challenges for pilots and response coordinators. The risk of midair collisions, for example, is high when pilots rely on their visuals and voice communication only, which is often the case in emergency response operations. In addition, insufficient or uncoordinated rescue demand information sharing might cause duplicate mission assignments and inefficiencies in search, rescue, and supply missions. To address these problems, JAXA has been developing an "Integrated aircraft operation system for disaster relief (D-NET)", which assists collection and sharing of disaster information through the integrated operation of aircraft such as helicopters, unmanned aerial vehicles (UAVs), and satellites, for efficient and safe rescue operations by disaster relief aircraft.

While the use and value of manned aircraft assets is well-established, unmanned aircraft systems (UAS) represent an emerging and versatile capability to aid in disaster response situations. The effectiveness and potential of UAS applications has already been demonstrated in recent disaster situations such as earthquakes in Japan [1] and hurricanes and wildfires in the United States [2]. Accordingly, sUAS are becoming indispensable tools for first responders and the deployment numbers reflect that through increased adoption by public safety agencies across the United States. There has also been a parallel growth in demand for the commercial application of sUAS. To support the broad application of sUAS across the commercial and public safety landscape, NASA has been engaged in collaborative research with the FAA, industry, academia, and other federal agencies to define the concept and approach to safely accommodating the projected demand in sUAS use.

Although the D-NET system has been successfully deployed and operational for disaster response management, it has not, to date, been adapted to incorporate the coordinated use of sUAS in its approach to asset allocation. To address this issue, NASA and JAXA have been working together to demonstrate the efficient and safe application of unmanned vehicles to disaster relief operations by leveraging the existing capabilities that have been developed and demonstrated as part of UTM and incorporating them into an interface with D-NET. This integration will enable disaster response efforts that take advantage of the benefits that manned and unmanned assets provide in a safe and coordinated manner.

\section{Integrated Aircraft Operation System for Disaster Relief (D-NET)}

\section{A. Research and Development Needs}

As discussed in the introduction, aircraft play a major role in disaster recovery, since damaged infrastructure often hinders the access to disaster-hit areas. Japan, being one of the most earthquake-prone countries in the world, has established an efficient practice of responding to disasters, by setting up disaster relief operation centers at various levels on short notice. These centers are often located at the local prefectural governments, and communicate directly with the disaster relief headquarters managed by the government. Disaster relief operation centers are not always in operation, however, as they are only formed when specific needs arise. One of the tasks of these centers is to manage aircraft operations in immediate post-disaster relief. This task is performed by dispatchers who oversee operations of multiple aircraft and coordinate with the disaster relief forces. Disaster relief aircraft, on the other hand, are involved in various missions, such as general reconnaissance, search, rescue, and transportation of personnel and goods. When the disaster is not spread over a large area, the number of vehicles involved allows the dispatchers to allocate the most appropriate mission to each vehicle and follow the mission progress, but as soon as the scale of the disaster grows, human controllers need a decision support system to allocate the available resources safely and optimally. Even in such a case, however, when aircraft belong to different organizations (e.g., Japan self-defense forces, fire departments and medical services), real-time telemetry and mission-related information cannot be shared, as no common operational platform exists.

To address the above issues, JAXA has been developing D-NET technologies for disaster relief along two main thrusts. First, to optimize data acquisition speeds and reduce the errors during voice transmissions when assigning missions, JAXA developed a system for real-time data transmission. The system enables a real-time connection between the pilot of a disaster relief aircraft and a ground server [3]. The system, being installed on fire department helicopters and used in nominal and off-nominal operations, has already proven to solve the problems of delayed and erroneous transmissions. However, relief operations in the immediate aftermath of the Great East Japan Earthquake, 
which hit on March 11, 2011, revealed the constraints of the existing systems when responding to wide area disasters. This helped define the second line of research of disaster relief technology at JAXA, which is the development of an integrated aircraft operation system to support information acquisition, mission planning, and decision making by utilizing and coordinating manned vehicles, unmanned vehicles, and satellites.

Despite the apparent need for such a disaster relief management system, there appears to be a lack of coordinated development work in this area. D-NET aims to develop a high-fidelity, portable, decision-support system to aid disaster relief operations regardless of their scale and location.

\section{B. System Objectives and Operational Concept}

The objective of D-NET is to acquire data efficiently from multiple sources such as satellites, helicopters, and unmanned aircraft systems to enable the analysis of these data in order to provide an optimal resource allocation and flight trajectory plan(s). These plans can then, in turn, be integrated into actual rescue operations. It is designed as a portable system for aircraft operation management in the immediate aftermath of a large-scale disaster. The operation concept of the system is shown in Fig. 1.

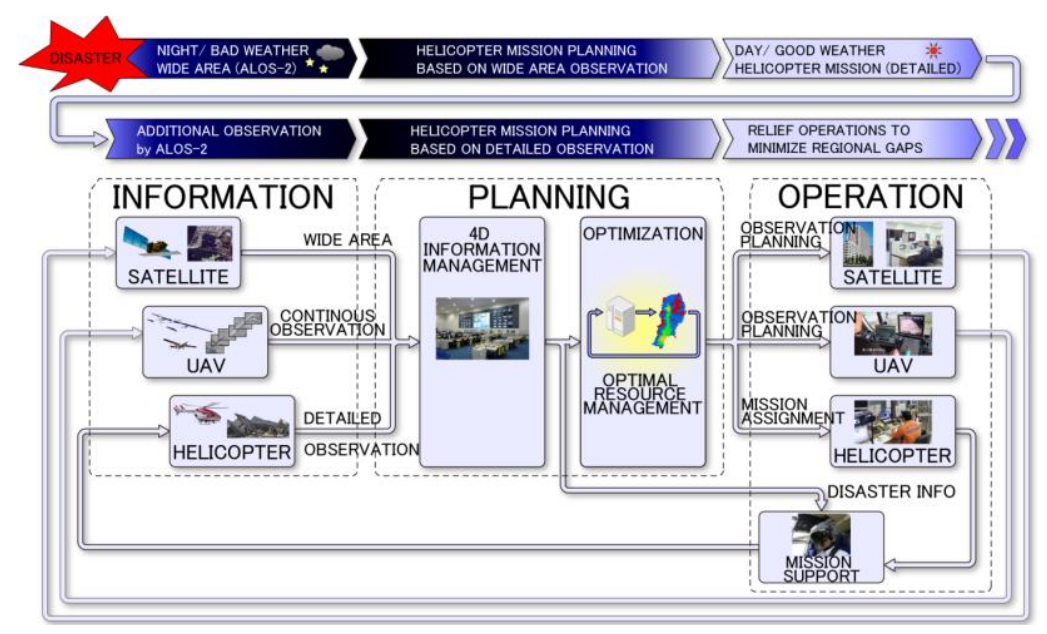

Fig. 1 D-NET operations.

The system has three main blocks: 1) data/information acquisition block, 2) optimal planning block and 3) operation execution block. The system employs three major types of vehicles as information sources: manned aircraft, unmanned aircraft, and land-observation satellites. D-NET optimizes the performance of each vehicle by assigning missions according to the vehicle's equipage, state, and location. Similar to the practice in current disaster relief operations, helicopters are responsible for providing detailed information on the extent of damage and status of evacuees. They are also involved in evacuee transportation missions, including stranded evacuees and people who have managed to reach an evacuation area, but have become endangered. Helicopters can also deliver medicines and other goods. Depending on the onboard equipment, helicopters (medical service helicopters in particular) are also used to transport patients from a hospital which has been stricken by the disaster to other safe areas/ hospitals.

Satellites, on the other hand, provide imagery over a wide disaster area even in the event of bad weather. Satellite imagery can be used to identify flooded areas [4], landslides, and bridge damage, for example [5]. A candidate satellite for use in support of such needs is JAXA's ALOS-2. D-NET uses the data provided by satellite imagery to aid disaster management authorities in their evaluation of overall damage and to generate optimal manned aircraft assignment and trajectories.

Unmanned Aircraft Systems (UAS) have already been used to monitor specific areas in Japan [6]. Furthermore, with the recent technological advances, broader applications such as supply delivery and continuous monitoring are likely to be realized in the near future. D-NET plans and assigns data acquisition missions to UAS in order to spare resources from the manned aircraft fleet so that more helicopters can be assigned to rescue missions.

So far, the focus of research on UAS applications in disaster relief, however, has been on single or a small number of aircraft operations. In the case of a large-scale disasters, hundreds of aircraft are deployed and engaged in search and rescue missions. Therefore, the overall coordination and integration of all aircraft are just as important, if not more, as the individual performance of any single vehicle. 


\section{Unmanned Aircraft System (UAS) Traffic Management (UTM)}

\section{A. Background}

In response to the clear growth in demand for the commercial application of sUAS in the United States, NASA embarked on a thrust of research to explore and define the concept, technologies, and guidelines necessary to provide a safe, scalable, efficient, and equitable approach to UAS traffic management [7]. This research effort has been conducted in close collaboration with the FAA and industry partners, and involves regular participation in targeted discussions, collaborative simulations, and live flight demonstrations. The initial parameters of UTM research have focused on the commercial application of small UAS (below 55 pounds) in low altitude, uncontrolled airspace where the UTM system serves as a separate but complementary airspace management system in relation to the established traditional domain of manned aviation. The approach to research of the UTM concept has been risk-based in terms of defining the operational environments in which to focus efforts on in a phased manner. Each phase of the research has mapped to what is referred to as a Technical Capability Level (TCL). Four TCLs have been defined where each TCL is characterized by a greater level of risk and complexity relative to the previous TCL with an associated increase in operational density and proximity to people.

\section{B. UTM Environment and Features}

Through this research effort, a federated architecture has been developed that supports a broad range of use cases and is scalable to provide support and services to increasing numbers of operator and service provider entrants. Fig. 2 presents the UTM architecture that has been developed thus far, which represents a separate but complementary system to the traditional National Airspace System (NAS). Unlike the NAS, however, air navigation service providers are not expected to manage traffic and provide separation services given the projected demand and complexity of operations. Instead, the UTM architecture has been developed to incorporate high levels of automation to provide such services. A key enabler of such an approach is the UAS Service Supplier (USS). At a minimum, the USS facilitates communication between the different components and operators in the ecosystem, supports operation planning, assists in strategic deconfliction and airspace management, and is a source of operational information for its operators and other service providers.

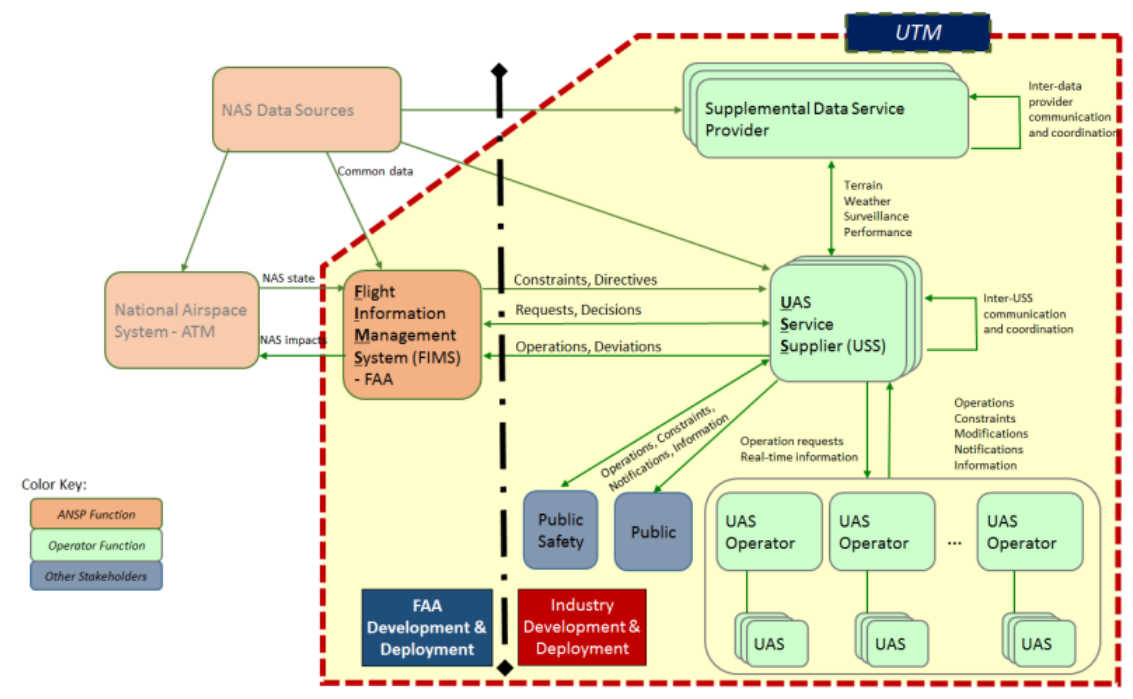

Fig. 2 Current architecture and information flow between major components of the UTM ecosystem.

With respect to the planning and deconfliction support provided by a USS, a key part of that process is what is referred to as an Operation Volume. An Operation Volume is a 4-dimensional volume that consists of a single or multi-segmented 3-dimensional polygonal volume with a temporal component that represents the time and duration that the volume(s), as part of an operation, will be active within the UTM system. The Operation Volume serves to signal the intent of an operator to perform an operation and maintain the vehicle within the bounds of the volume(s) at all times. A USS also uses the Operation Volume for strategic deconfliction of airspace by checking proposed volumes from other operators within the same USS and from other USSs to ensure that there is no overlap in time and space of volumes. This check serves as an initial layer of safety and provides a level of assurance to the operator 
and potential airspace managers (e.g., in disaster response situations) that the operation can be performed with reduced concern of sharing the airspace with other vehicles at the same time. Figure 3 presents operation volumes that were active during a live UTM flight demonstration. As shown in Fig. 3, having an awareness of where operations are planned or are currently taking place can aid operators and managers in planning and managing their own operations and allocation of resources.

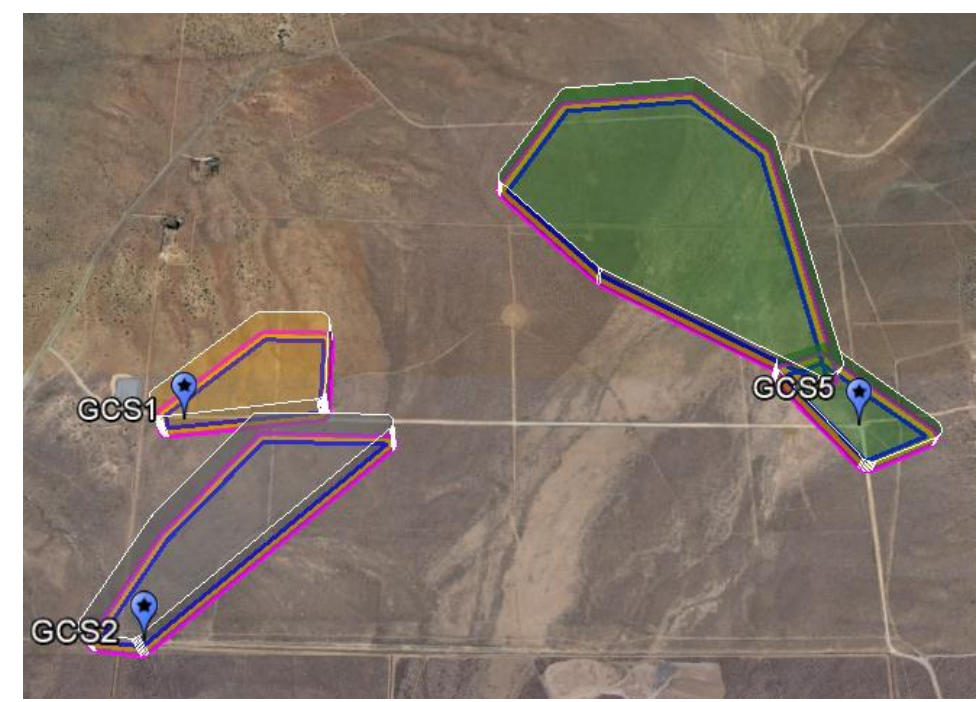

Fig. 3 Example of Operation Volumes used in a UTM flight demonstration

In addition to planning support and deconfliction of Operation Volumes, USSs can also provide a level of monitoring and conformance checking as a means of ensuring that a given flight is performing appropriately. The current approach in testing is for position updates to be submitted to the USS at a defined rate (e.g., $1 \mathrm{~Hz})$ throughout the entirety of an operation. Each update is checked whether it is inside the Operation Volume or outside in order to determine the flight's conformance. If a given flight breaches its volume, alerting takes place not only to the associated operator, but to other nearby operations to aid in situation awareness and response planning. The functions of a USS in providing planning support, deconfliction, and flight monitoring of UAS within UTM are particularly relevant in the current research efforts to integrate UTM and D-NET. These functions will be the mechanism by which sUAS are managed and able to be incorporated into the overall strategic planning, allocation, and management of manned and unmanned assets in real-time.

\section{UTM Operations}

\section{Example UTM Operation}

The basic steps to performing an operation supported by UTM are illustrated to provide some context for the flow of information that will be necessary for the D-NET system and UTM to coordinate an effective and integrated response. For an operation to be supported through UTM, an operator first identifies an area for the flight and, depending on the intended operation, develops a flight plan for the vehicle (e.g., Fig 4 left panel). There is no requirement on how the plan is developed, however, which makes it possible for plans to not only be developed manually through flight planning software, but also through flight planning services that could provide optimized plans based on various parameters. Regardless of method, for that plan to be communicated to the UTM system, a polygonal volume or set of volume segments that encapsulates the developed flight plan or intended area of operations is constructed by the operator (Fig. 4 right panel). The initial volume, referred to as a flight geography, represents a $3 \mathrm{D}$ volume (Fig. 5) of where an intended operation is to occur with an associated temporal component that defines the duration for when that volume or segment will be active. Once submitted to the supporting USS, additional buffers can be added to the initial flight geography to account for uncertainties. The overall resulting final volume(s) that will be accounted for within the USS and communicated to the USS network and supporting services -if present- is the Operation Volume. The Operation Volume serves to signal the intent of the operator to use that airspace for the defined duration and serves as an initial layer of safety and awareness for other operators planning operations in the vicinity. 

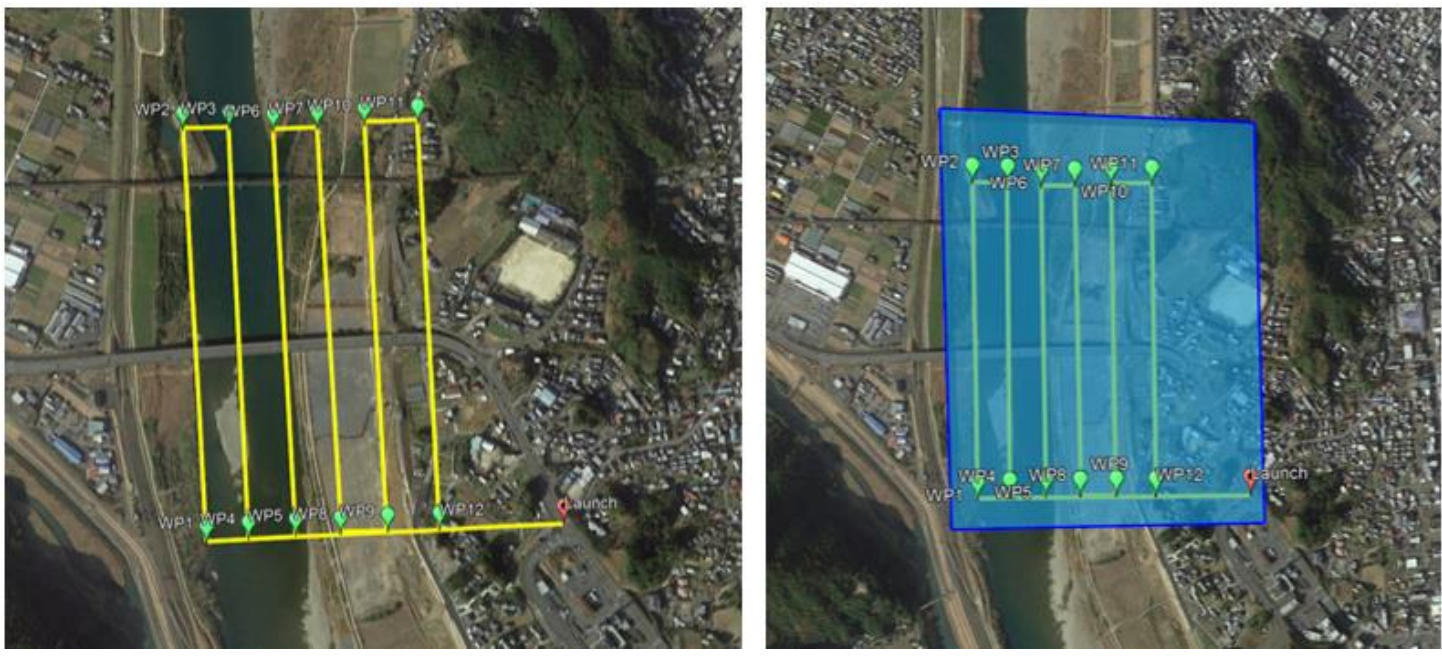

Fig. 4 Example of UAS flight plan (left) and associated Operation Volume (right)

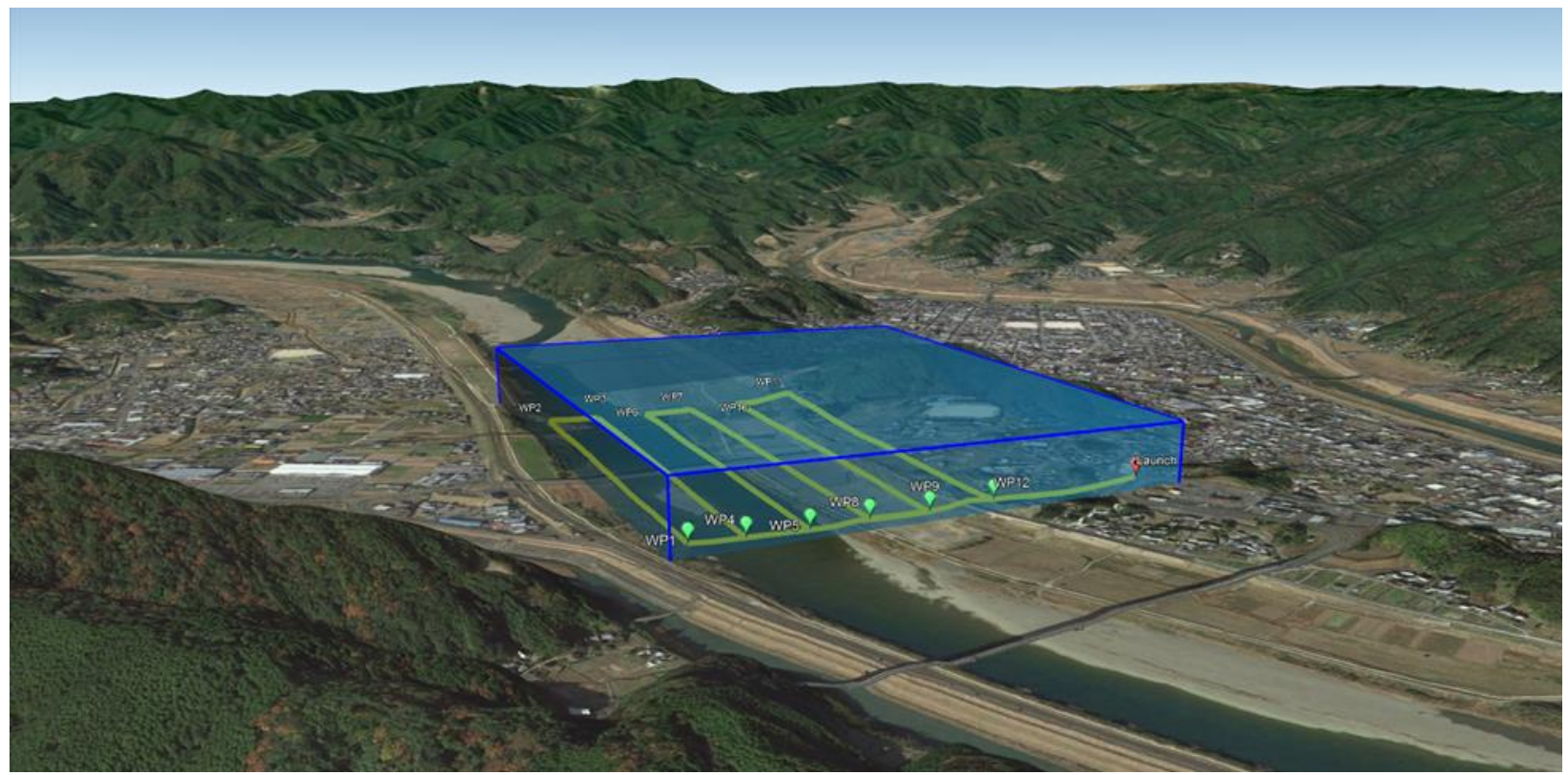

Fig. 5 Profile of Operation Volume to illustrate its 3-dimensional composition

After the Operation Volume for a proposed UAS operation is established, the USS performs checks on the airspace to ensure that there are no overlaps with other operations or airspace constraints (e.g., airports or restricted areas). Given the temporal aspect of Operation Volumes, geographic overlaps are permitted between operations as long as they are separated in time. Once the USS determines that the submitted Operation Volume is clear of other operations and constraints, the operator is notified that it is 'Accepted' and the operation can commence within the specified times. When the operation becomes 'Active,' position data for the flight is sent from the vehicle to the USS via a UTM client interface (typically integrated with a Ground Control Station). While 'Active,' position updates are required at regular intervals to the USS, and each of the updates is checked in relation to the bounds of the Operation Volume as a means of conformance monitoring. If a vehicle nears the outer bounds of the volume, a 'Non-Conforming' message is sent to alert the operator of the situation and provide the opportunity to bring the flight back into conformance. If the operator is unable to control the vehicle and avoid a breach of the Operation Volume, the operation transitions to a 'Rogue' state. At this point, it has been determined that the operation is not under sufficient control to continue in the airspace and must land and close in order to address the contributing factors. If, however, the flight is able to 
remain within the Operation Volume throughout its mission (the more typical scenario), the vehicle simply transitions to its landing and recovery location. Position updates are stopped at this point and the operation is 'Closed.'

The preceding was an overview of a single UTM operation supported by a USS. The number of operations is, however, scalable to enable multiple simultaneous operations where the USS provides broad support for planning, airspace management, and situation awareness. Fig. 6 presents an additional example where two operations have been planned in relative proximity. Of note in this example is the use of different types of volume geometries to support different operational needs. While the singular Operation Volume in Fig. 6 is meant to support a search scan pattern and more conducive for opportunistic and dynamic flights, the additional operation makes use of segmented Operation Volumes for a more deterministic flight and potentially more efficient use of airspace in which volume segments expire sequentially and allow for use of the cleared airspace by additional operations. Combinations of different geometries are also possible as well as the ability to dynamically re-plan Operation Volumes to account for contingencies and other responses to airspace requirements.
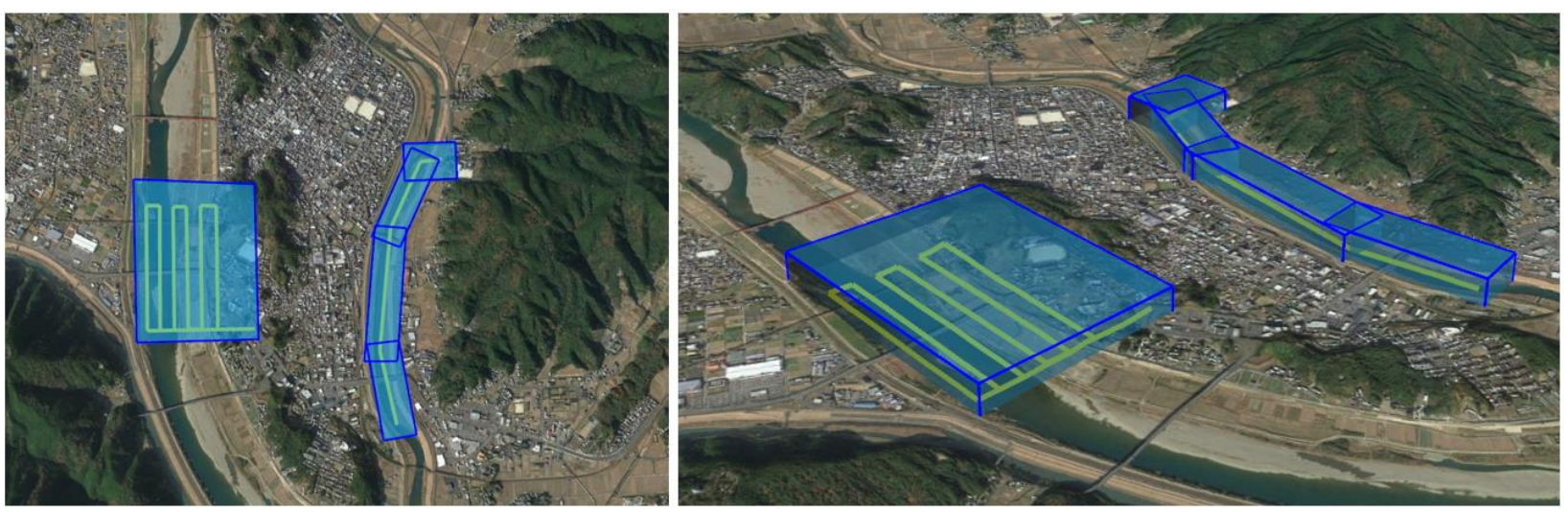

Fig. 6 Multiple operations with single area and multi-segmented Operation Volumes

\section{Priority Operations in UTM}

In consideration of operational environments where there is a need for a distinction between nominal operations and those that need priority, UTM incorporates the capability for certain operations to have an associated priority status with an associated level of priority access to the airspace. Priority status is declared as part of an operation submission from authorized entities that have elevated privileges. Operations that have an associated priority status are allowed to overlap in time and space with other Operation Volumes of active and proposed operations. The affected non-priority operations are notified via the USS that their operation conflicts with priority use airspace and that a response is required to resolve the airspace conflict through re-planning or closure. The approach to priority operations is particularly relevant in public safety and disaster response situations where the use of UAS is playing increasingly important roles in the ability of operating organizations to provide expedited search and on-scene awareness with reduced risk to response personnel.

\section{UTM flight testing}

Throughout the course of NASA's UTM research, live flight tests have been an integral part of the research process. The ability to apply the architecture in a live environment subject to the effects of weather and other environmental impacts with industry partners incorporating their technology implementations is vital to understanding the issues and considerations that need to be accounted for as the research progresses. As part of the research plan, each TCL has been scheduled to incorporate at least one test at a given site with close coordination and collaboration with NASA and industry partners. To date, tests have been performed across TCLs 1 through 3 with many industry partners testing a diverse set of technologies spanning implementations ranging from USSs, vehicles, control software, surveillance, communication approaches, etc. Each of the testing events incorporated elements of the given TCL such that TCL 1, for example, involved visual line-of-sight operations in a low density environment [8]. TCL 2 testing involved more complex operations and interactions with beyond visual line-of-sight missions, higher densities of traffic, and priority operations and associated airspace procedures $[9,10]$. The testing for TCL 3 is in progress as of this writing, but the complexity of tests builds upon the previous tests with a focus on areas related to sense and avoid, data exchanges, communications and navigation, and concept development. Additional testing is planned as part of the UTM and D-NET integration as a complement to the TCL tests and is 
intended to give insight into the value and benefit that UTM provides in disaster response situations. Further details of this planned test will be provided in a subsequent section of this paper.

\section{Concept of Operations of UTM/D-NET Integrated System}

\section{Basic Concept of Operations}

The integrated system between JAXA's D-NET and NASA's UTM is focused on the safe and efficient use of sUASs in immediate post-disaster relief operations. The portability of both systems meets the needs of such relief operations greatly. The integrated system operations can be described in two main stages- planning and in-flight. At the flight planning stage (Fig. 7 left panel), D-NET is responsible for the generation of optimal flight plans for both manned and unmanned aircraft. D-NET contains data on the available aircraft fleet and onboard equipment, as well as real-time data on reconnaissance and rescue mission demands. The optimization subsystem uses the above data to assign missions and generate flight trajectories for all aircraft. Since there are various types of manned aircraft, the system can provide manned aircraft operational volumes, analogous to minimum separation required in nominal civil aircraft operations. These volumes are then submitted to UTM. Similarly, unmanned aircraft flight plans are submitted to UTM, where they can be either accepted when they meet the safety constraints imbedded in the system, or otherwise rejected. The flight plan acceptance/rejection is feedback to D-NET and input for further planning and optimization.

At the in-flight stage (Fig.7 right panel), D-NET provides the tracking data of the aircraft engaged in disaster relief missions to UTM. UTM can then issue alerts if unmanned aircraft do not conform to their operation volumes, or if a manned aircraft is expected to enter the airspace in use. Performing conflict detection at both planning and in-flight stages contributes to safe mission execution.

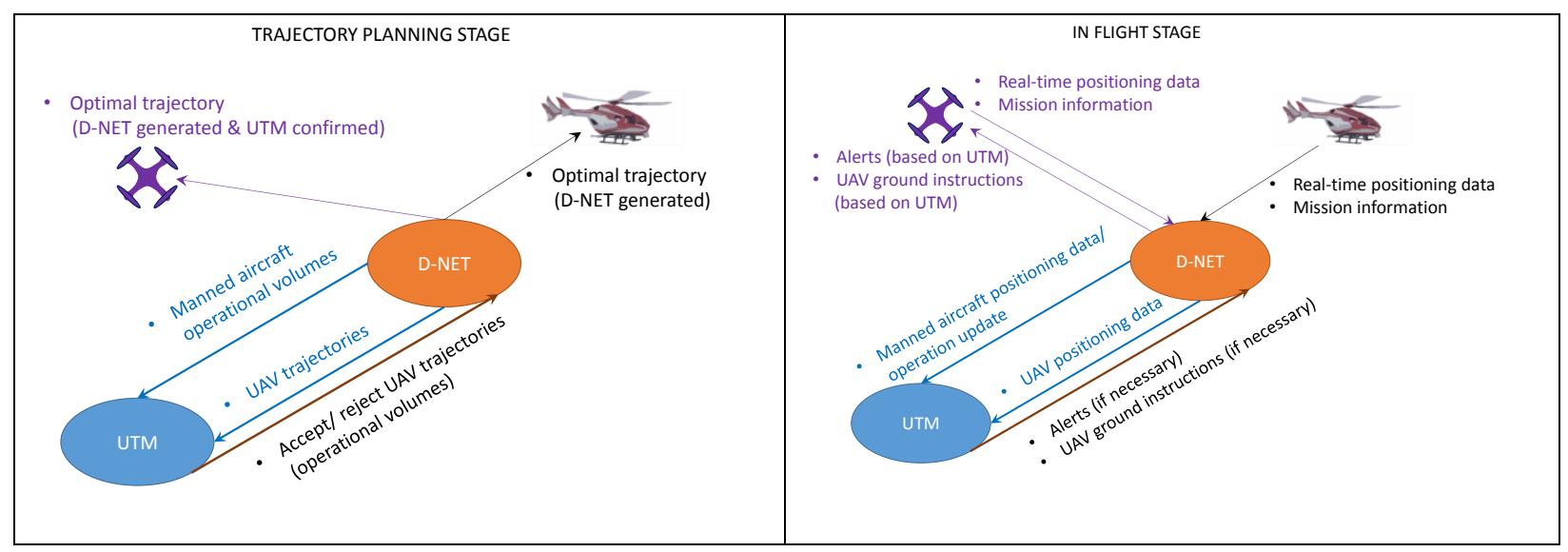

Fig.7. UTM and D-NET conceptual interaction at the flight planning (left) and in-flight stages (right)

\section{E. Architecture and Concept of Operations Exploration}

The steps taken thus far in the integration process between UTM and D-NET established an initial interface and capability necessary for managing manned and unmanned assets in a disaster response environment. The main components of the integrated system are UTM, D-NET, UAS ground stations, and vehicles. Apart from these, external components like aircraft databases, satellites, and supplementary data providers aid the overall mission assignment decided in D-NET. It should be noted that the external components are not limited to the ones shown here, but for the purposes of data flow explanation the above three would suffice.

The proposed operational flow is shown in Fig. 8. First, D-NET generates vehicle mission assignments and flight plans based on information from available resources (obtained through the aircraft database), satellite imagery showing flooded areas, for example, and disaster area information. With this input data, D-NET's planning block creates optimal mission assignment of the available disaster relief manned and unmanned aircraft. During this process, basic operational constraints based on vehicle capabilities and minimum required separation are imposed. At the current integration stage of UTM and D-NET, UAS are considered to operate in UAS assigned airspace only. Once the flight plans are generated, they are sent to UTM for verification. UTM can then either accept or reject the submitted UAS flight plan and send the decision information back to D-NET. If a flight plan is accepted, D-NET will send it to the UAS ground base, which will convey it to the vehicle. If a plan is rejected, D-NET will correct it by re-optimizing the plan against the rest of the missions and re-submit to UTM. This process is repeated as necessary. UTM makes the decision on acceptance/rejection based on its own criteria which do not need to become visible to D-NET. This 
"double-checking" increases the safety of UAS operations, but might affect their efficiency. This tradeoff will be verified in future flight tests. UTM also sends operational volumes along with the accepted flight plans, which are available to D-NET. Once UAS mission is active, position data is sent from the UAS though the ground station and D-NET to UTM, which checks their conformance with submitted flight plans and assigned operational volumes. When non-conformance is detected, an alert is sent to D-NET requiring the UAS to adjust its behavior. Another kind of alert is associated with manned aircraft approaching and/or entering the assigned UAS airspace. This is a functionality specific to disaster relief operations, which arose after discussions with first responders and disaster relief aircraft dispatchers. At present, the most likely role of UAS is in reconnaissance. When a critically injured victim is found by a UAS, for example, a medevac helicopter must reach this victim and transport them to the nearest safe location as soon as possible. This scenario will require a manned medevac helicopter to enter the UAS assigned airspace. To enable such interaction, D-NET submits manned aircraft telemetry to UTM which uses is to issue the necessary alert to the UAS operator.

Flight plans, operational volumes, and telemetry will be visualized on D-NET's interface and used by response management at local disaster relief centers to follow the mission progress. This visualization is also expected to increase the situational awareness and reduce any redundant communication regarding position updates and mission status.

The architecture described above is only a preliminary version and will be tested in disaster drill flight tests planned for the autumn of 2018. Developing the architecture is also part of the overall exploration of an overarching concept of operations that will define how the integrated UTM/D-NET system will be tested and applied according to real world use cases and concept elements. This exploration will depend on scenario development that examines different types of disasters and their scale, assumed chain of command of first responders, vehicle performance, and the environment including communication availability.

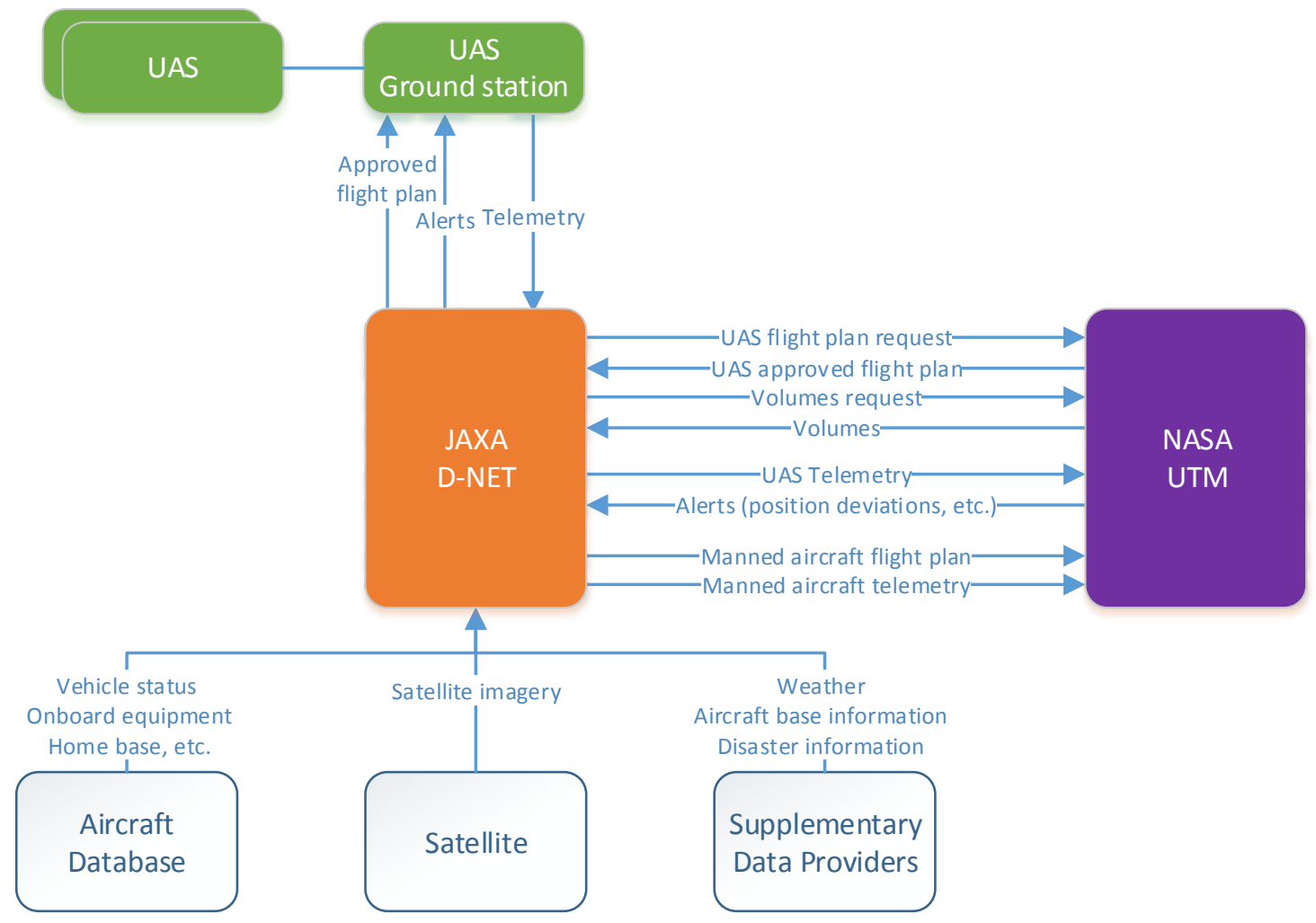

Fig. 8 Potential architecture and information flow between D-NET and UTM

\section{F. Interface Development and Evaluations}

UTM and D-NET connect through an interface developed to meet the operational requirements outlined above. JAXA developed an initial version of the interface in early 2017, based on commonly agreed design requirements. In order to test the performance of the interface, tests were conducted to model sample disaster relief operations in Japan. Shown in Fig. 9 are two sample flight plans for UAS that were submitted to UTM by the D-NET flight planner. In 
this example, the flight plan of the second vehicle was rejected due to its operation volume overlapping with the volume previously submitted by the first vehicle. The planned volume was then re-optimized and time-shifted by DNET in order to avoid the overlap and submitted as a new operation to UTM. As a result, both flight plans were successfully accepted (Fig. 9). During this test, UTM and D-NET servers were located in the US and Japan, respectively, and serve as the likely configuration for testing in the near future.
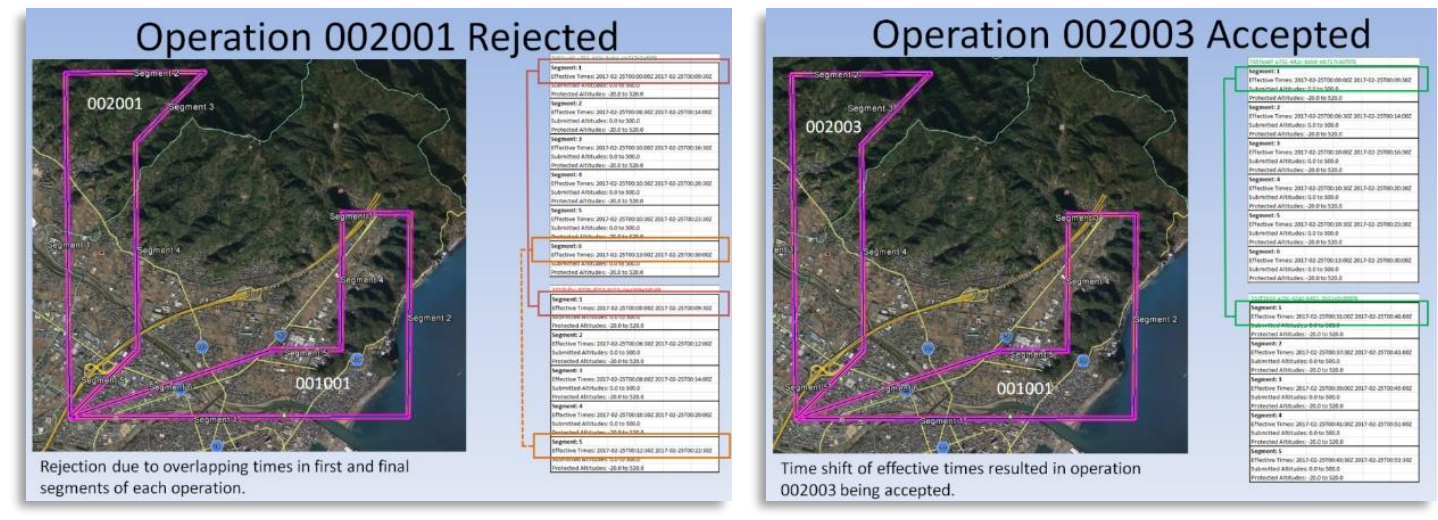

Fig. 9 UTM/D-NET collaborative simulation example

The next step of the integration process is the transmission of UAS positions from D-NET to UTM. Once telemetry is available to UTM, it will be able to verify the UAS is flying in the volumes assigned to its operation. If, for some reason, the UAS fails to provide sufficient position reports or leaves the assigned volume, it will be declared as nonconforming and an alert will be sent to D-NET.

One of the main characteristics of D-NET is the integration of both manned and unmanned vehicles. UTM will handle unmanned vehicles only, but flight plan and position information of manned vehicles will be transmitted through the interface from D-NET to UTM. UTM will treat manned aircraft as priority vehicles and use their positions to alert UAS as necessary.

Since D-NET is meant to be used by disaster relief effort planners and dispatchers, for it to function as a decision support tool, visualization is important. A prototype of D-NET's human interface has been tested in a large-scale disaster drill in Sep 1, 2015. A sample screenshot is shown in Fig. 1. D-NET visualizes flooded areas (shown in shaded blue) based on data and analysis of satellite imagery. Flooded areas identified through sources other than satellite imagery are shown as shaded light green polygons. Landslides are marked by light green crosses. The real-time position and identification information of helicopters with the D-NET system onboard can also be seen.

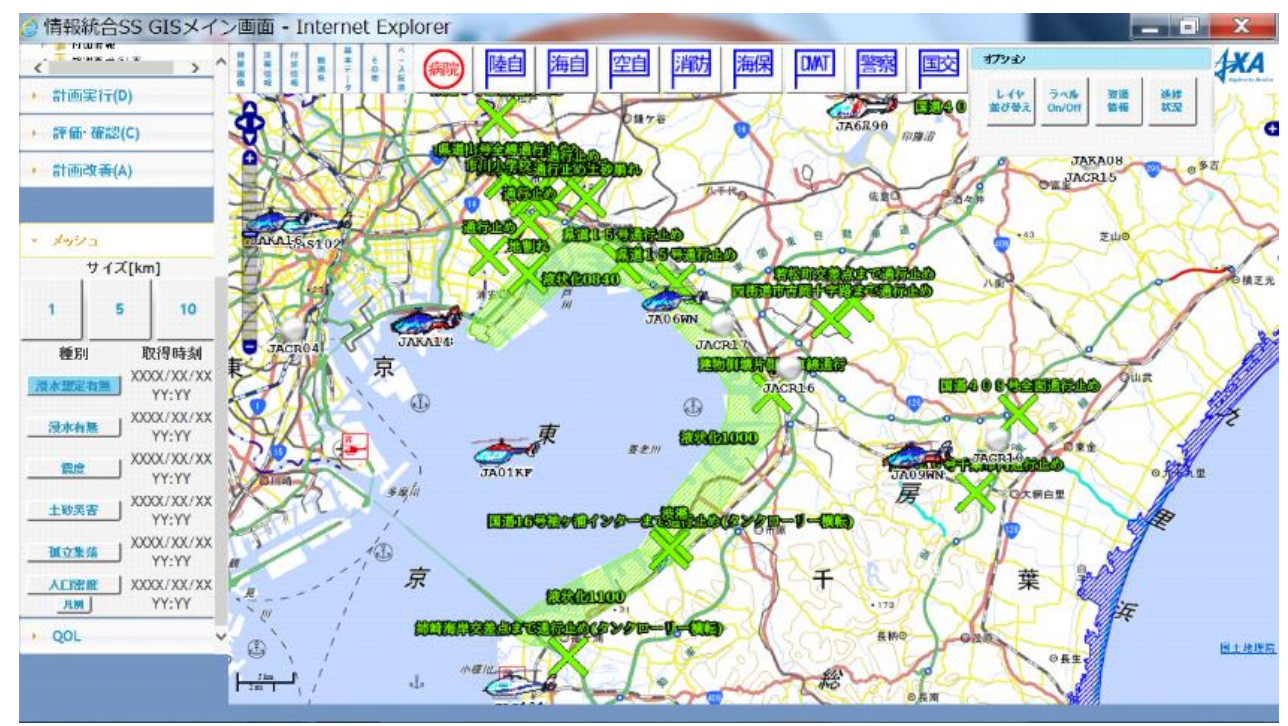

Fig. 10. Sample screenshot of D-NET visualization tool 
A number of visualizations and user interfaces have been developed throughout the course of the UTM research effort thus far. In an ongoing effort, a group of developers, engineers, and interface design researchers have worked together to understand the usability requirements for those interacting with the UTM research prototype and how to work with and help define the reference specifications in order to display UTM information most effectively. These tools have been particularly useful in providing situation awareness and understanding for operators and test coordinators during live flight demonstrations. In early tests, flight crews often did not have the benefit of visualizations to aid in the conduct of their operations because they initially thought that it would be unnecessary. However, once multiple operations conducted by independent operators started to take place in close proximity, it became immediately apparent that a user interface with real-time access to UTM information about their own operation and others nearby was a clear necessity.

Fig. 11 presents an example of the Insight UTM (iUTM) interface that has been developed for use as a mobile application on phones and tablets. What iUTM and similar tools provide its users with is access to UTM information in various forms to aid in planning and executing operations with real-time status updates for monitoring and troubleshooting issues when necessary. In the iUTM example in Fig. 11, the graphical display on the right gives users an understanding of the overall airspace and where operations are in relation to one another. This feature is used to assist in planning safely separated operations without the need to use strategic deconfliction on a trial and error basis. Understanding the airspace also helps with planning contingency responses to changes in the airspace whether it is in response to nearby operations that are in an off-nominal state or due to airspace restrictions that have been implemented and require an expedited response. In addition to the airspace view, the iUTM application also provides users with an operations list view (as shown on the left of Fig. 11). This view gives the user a quick overview of operations within the system and their status. Each list entry is a gateway into a detailed view of the selected operation with, for example, a record of messages received, operation state, and vehicle state information.

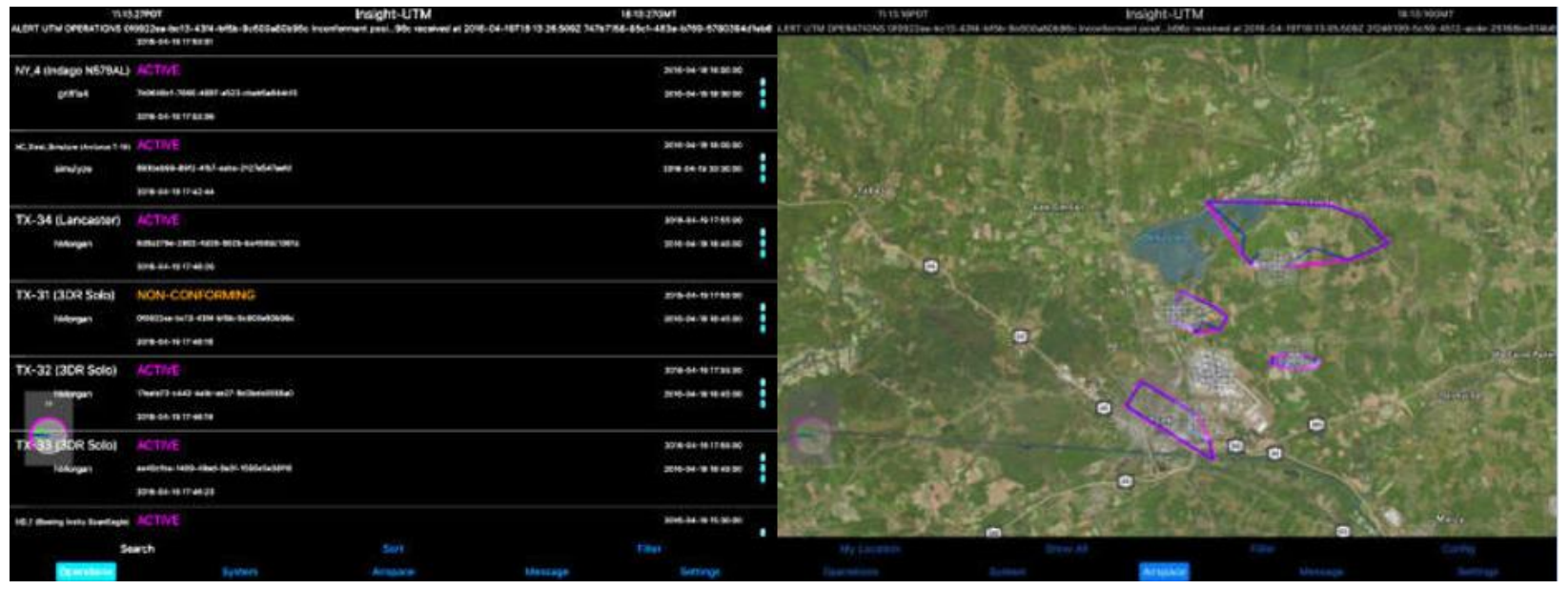

Fig. 11 Interactive user interface for UTM operations

UTM/D-NET integrated visualization will be based on the current D-NET interface and incorporate elements of the visualizations developed as part of UTM. Apart from the information already discussed above, flight plans and operational volumes will also be visualized. Flight plans are submitted from D-NET to UTM as line segments defined by time-stamped waypoints. In the sample screenshot in Fig. 12, flight plans are shown as light blue lines. The aircraft's position is shown by the green arrow. Operational volume information, sent from UTM to D-NET will be used to visualize the area to which a flight should be confined. The visualization tool will distinguish between active (pink) and non-active (yellow) volumes. These volumes will help both the disaster relief local managers and vehicle operators to follow the mission progress in real-time. Specific color choices are still subject to change, and the disaster drill system performance verification will be used as the first testbed to obtain valuable feedback on this humanmachine interface. 


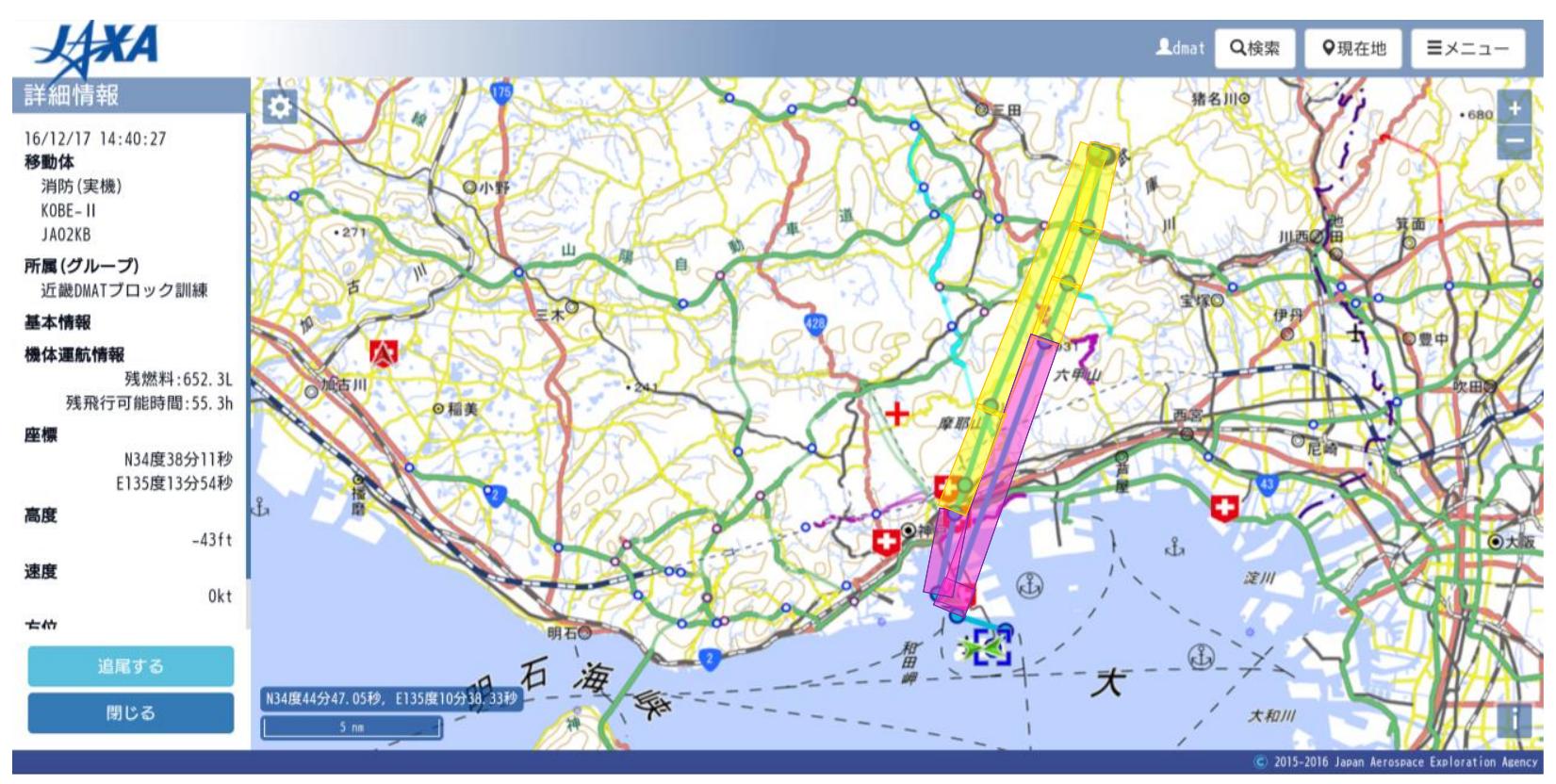

Fig. 12 Example of proposed D-NET/UTM integrated visualization

\section{VI. sUAS Operational Environments in Disasters: Lessons Learned and Use Case Development}

In addition to the current integration and development work for the UTM/D-NET system in terms of its architecture, information flows, and visualizations, a definition of the concept of operations and use cases is necessary in defining how the integrated system will be used and what the most effective approach to testing is. In developing the concept and related use cases, the lessons learned from recent disaster events in Japan serve as guidance for what considerations are necessary and what critical gaps have been identified that the application of the UTM/D-NET system would address. The issues of disaster classification and associated response, communications infrastructure, airspace management, and UAS capabilities are considered.

\section{A. Disaster Classification According to Scale and Corresponding Operational Environment}

The established cellular data communication network is a potential candidate for the D-NET/UTM connection from sUAS operators. However, experience has shown that the cellular network is not always reliable especially in the case of large-scale disaster relief operations (Table. 1). For example, in the case of the Great East Japan Earthquake and Tsunami in 2011, the cellular communication network service was not available over a vast area of approximately 60 kilometers for as long as 7 weeks. In the case of the Kumamoto Earthquake in 2016, depending on the carrier, there was no coverage within a $20 \mathrm{~km}$-wide area. Damage to the cellular network infrastructure (towers, communication wires) itself was not critical but power cuts caused most cellular network issues $-85.3 \%$ in case of a wide area disaster. Considering these lessons learned from past disasters, the ground communication environment largely depends on the scale of the disaster and extent of damage. sUAS operational scenarios must be considered accordingly.

Table. 1 Example of Recent Disasters in Japan

\begin{tabular}{|c|c|c|c|}
\hline Disasters & $\begin{array}{l}\text { Tohoku Earthquake and Tsunami, } \\
2011 \text { [11] }\end{array}$ & $\begin{array}{l}\text { Kumamoto Earthquake, } 2016 \\
{[12,13]}\end{array}$ & $\begin{array}{l}\text { Hiroshima Landslide, } 2014 \\
\text { [14] }\end{array}$ \\
\hline Characteristic & $\begin{array}{l}\text { Huge, wide area disaster } \\
\text { (multiple prefectures, approx. } 500 \\
\text { km range) }\end{array}$ & $\begin{array}{l}\text { Middle scale disaster } \\
\text { (single prefecture, approx. } 50 \\
\text { km range) }\end{array}$ & $\begin{array}{l}\text { Local disaster } \\
\text { (single city level, approx. } 4 \\
\text { km range) }\end{array}$ \\
\hline
\end{tabular}




\begin{tabular}{|c|c|c|c|}
\hline Scales & Magnitude $9.0(\mathrm{Mw})$ & Magnitude $7.0(\mathrm{Mw})$ & $\begin{array}{l}8.56 \text { in of extremely heavy } \\
\text { rain in short time }\end{array}$ \\
\hline Causalities & 15,895 deaths, 2,539 missing & 267 deaths & 77 deaths \\
\hline $\begin{array}{l}\text { Deployed disaster } \\
\text { response manned } \\
\text { aircraft }\end{array}$ & $>300$ helicopters deployed & 18 helicopters deployed & 11 helicopters deployed \\
\hline UAS operations & $\begin{array}{l}\text { - One fixed wing UAS flew BVLOS } \\
\text { reconnaissance mission of damaged } \\
\text { nuclear power plant } \\
\text { - Global Hawk flew over the nuclear } \\
\text { power plant. }\end{array}$ & $\begin{array}{l}\text { - Many VLOS sUAS (multi- } \\
\text { rotors) were deployed by } \\
\text { governmental institutes, } \\
\text { universities, companies, NPOs, } \\
\text { and news media. }\end{array}$ & $\begin{array}{l}\text { - Measurement companies } \\
\text { flew VLOS sUAS } \\
\text { - News media sUAS flew } \\
\text { close to JGSDF helicopter } \\
\text { but the operator seemed to } \\
\text { be unaware of the risk }\end{array}$ \\
\hline Cellular services & $\begin{array}{l}\text { - Number of stations stopped } \\
\text { service: } 29,000 \text { ( } 85.3 \% \text { were caused } \\
\text { by commercial electric power } \\
\text { outage) }[15] \\
\text { - Cellular service stopped over a } \\
\text { wide area ( } 60 \mathrm{~km} \text { maximum range) } \\
\text { - About } 7 \text { weeks for recovery }\end{array}$ & $\begin{array}{l}\text { - Number of stations stopped } \\
\text { service: } 400(74.5 \% \text { were caused } \\
\text { by commercial electric power } \\
\text { outage) [16] } \\
\text { - Cellular service stopped over a } \\
\text { wide area ( } 20 \mathrm{~km} \text { maximum } \\
\text { range depending on carrier) } \\
\text { - About } 2 \text { weeks for recovery }\end{array}$ & $\begin{array}{l}\text { - Number of stations stopped } \\
\text { service: N/A [17] } \\
\text {-Minimal impact to cellular } \\
\text { service } \\
\text { - N/A }\end{array}$ \\
\hline
\end{tabular}

\section{B. Temporary VFR Advisory Airspace in Japan}

As for the large scale disaster in 2011, few UASs were available for the disaster response. However, since 2016 a large number of sUAS have been deployed by local governments in disaster and response situations. Although sUAS are supposed to operate within VLOS and remain under positive control, the separation between manned disaster response aircraft and VLOS sUAS is of serious concern. As a result, a Notice to Airmen (NOTAM) was published to set temporary VFR advisory airspace over the Kumamoto search and rescue activity area [18]. This airspace was controlled by the Japanese Ground Self-Defense Force (JGSDF), which operated a significant number of helicopters in the immediate post-disaster response. All VFR aircraft were issued an advisory so that the high-density airspace could be managed. At the same time, the Japan Civil Aviation Bureau (JCAB) announced a recommendation to refrain from sUAS operations in the airspace given the uncertainty. Therefore, it can be said that even though sUAS are considered very important tools for disaster responses, a safe operational environment with common situation awareness has not been established yet. The UTM/D-NET integration is intended to address this problem and establish safe operation environment for both manned and unmanned aircraft in disaster situations..

\section{C. sUAS Use Case Categories in Disaster Situations}

Considering varying disaster scales and the performance of sUAS, operations can be categorized into three types according to their use case. Fig. 13 presents three use case categorizations that vary according to area and location of damage, UAS availability, communications coverage, and operating entities. In use case A, VLOS operations are managed by local operators inside the severely damaged area. There are a number of commercial off-the-shelf (COTS) sUAS deployed by local response organizations. However, their performance may be limited and cannot rely on UTM/D-NET support without ground communication infrastructure available. Use case B represents operations in a lightly damaged area where disaster responders may use industrial grade sUAS equipped with SATCOM that allow UTM/D-NET connection without ground-based infrastructure. In this case, ground access to the disaster area is limited or restricted such that the sUAS operator can access only the relatively undamaged area just after the disaster. Use case $\mathrm{C}$ involves BVLOS operations with high performance sUAS which may be operated by special disaster responders. The environment in this case provides high performance and full functionality for BVLOS due to the ability to operate from the non-damaged area into the damaged area. Based on the categorizations presented, the current D-NET/UTM integration system can provide services and support in use cases B and C. However, use case A is problematic because of the degraded communications environment in which there is no D-NET/UTM connection. However, such issues are not insurmountable given available technologies and the development of potential solutions. Avenues to address all use cases through the integration efforts and testing will be explored as the research progresses. 


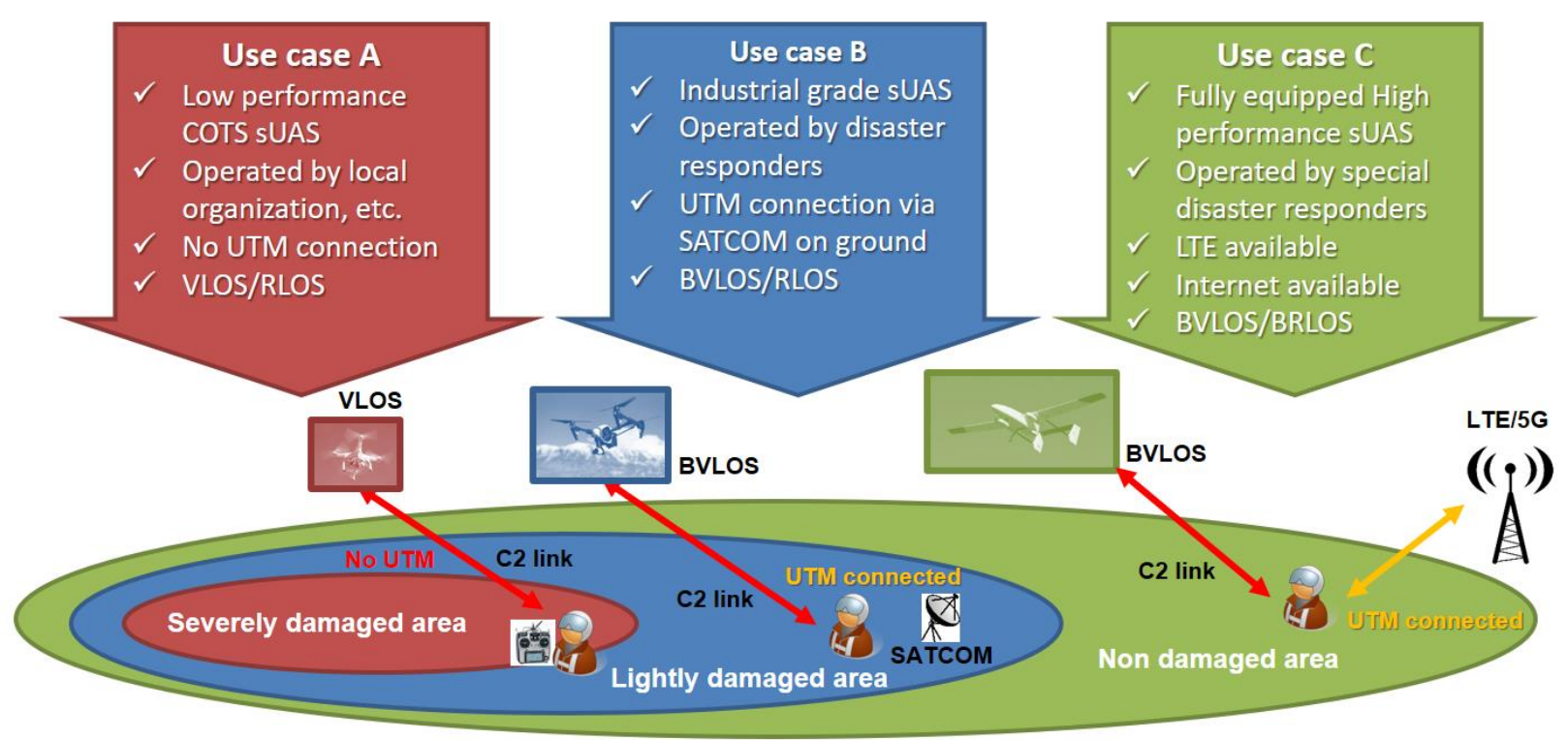

Fig. 13 Operation cases in a disaster response situation with integrated D-NET and UTM interactions.

\section{VII.Next Steps}

The architecture and flow of information between D-NET and UTM has been established and is currently in development. Collaborative simulations are planned to test the integration of the two systems, which will not only examine the functionality and effectiveness of the integration but also provide insight into the visualization's usability and requirements for the incorporation of manned aircraft as priority operations. The Concept of Operations described previously serves as a foundational reference for the scenarios that will be used for constructing the simulation. The successful completion of a simulation will pave the way for participation in a planned disaster drill in Japan that will involve multiple stakeholders and entities related to coordinated disaster response at local and national levels. Manned and unmanned assets are planned for use in a coordinated manner with the UTM/D-NET integration acting as the enabling capability.

\section{Conclusion}

NASA and JAXA have been working together to define a concept of operations for the management of manned assets and sUAS through the integration of UTM and D-NET to support disaster mitigation. Initial work was been performed to begin the interface between the two systems with successful submissions performed from Japan. Additional work to more fully integrate UTM and D-NET and explore the overarching concept is ongoing with a clear path forward. Participation in a live disaster drill where D-NET and UTM are providing planners and operations managers the ability to safely and effectively deploy manned and unmanned assets in support of a coordinated response effort will serve as a valuable demonstration of the integration effort and efficacy of the underlying concept. A followon publication is planned that will detail the final state of the UTM/D-NET integration, its application in the disaster drill, and operational results.

\section{References}

[1] Torii, T., and Sanada, Y., "Radiation measurement by unmanned aircraft after Fukushima Daiichi nuclear power plant accident," in Proc. Symp. ICAO, Montreal, QC, Canada, Mar. 2015. [Online]. URL: http://www.icao.int/Meetings/ RPAS/RPASSymposiumPresentation/Day\%201\%20Session\%202\%20 Massaki\%20Nakadate.pdf [retrieved 9 November 2017]

[2] Justin Adams, David Merrick, Robin Murphy, "Small Unmanned Aerial Systems at Hurricanes Harvey and Irma," FSU Center for Disaster Risk Policy Technical Report 2017, URL: http://em.fsu.edu/docs/emhs-cdrp-tr20170901-harvey-irma.pdf [retrieved 9 November 2017] 
[3] Kobayashi, K., Okuno, Y., \& Ishii, H. (2016) Development of Disaster Relief Aircraft Management System Network (D-NET), Journal of the Japan Society for Aeronautical and Space Sciences, Vol. 64, No. 1, 2016.

[4] Emergency observation and initial flood assessment in the Barun river basin, Nepal by ALOS-2, http://www.eorc.jaxa.jp/ALOS-2/en/img_up/dis_pal2_npl-flood_20170517.htm [accessed 9 November 2017]

[5] Global Landslide Catalog Aids View From Space, https://www.nasa.gov/feature/goddard/global-landslide-catalogaids-view-from-space, [accessed 9 November 2017]

[6] 無人航空機（UＡＶ） を活用した国土地理院の災害対応, http://www.gsi.go.jp/common/000150883.pdf, [retrieved 9 November 2017]

[7] Kopardekar, P., Rios, J., Prevot, T., Johnson, M., Jung, J., \& Robinson, J. E. I. (2016). Unmanned Aircraft System Traffic Management (UTM) Concept of Operations. AIAA Aviation, Technology, Integration, and Operations Conference.

[8] Rios, J., Mulfinger, D., Homola, J., \& Venkatesan, P. (2016) NASA UAS Traffic Management National Campaign - Operations Across Six UAS Test Sites. IEEE-DASC 2016, September 26-29, 2016, Sacramento, CA.

[9] Johnson, M., Jung, J., Rios, J., Mercer, J., Homola, J., Prevot, T., Mulfinger, D., \& Kopardekar, P. (2017) Flight Test Evaluation of an Unmanned Aircraft System Traffic Management (UTM) Concept for Multiple Beyond-Visual-Line-of-Sight Operations. 12th USA/Europe Air Traffic Management Research and Development Seminar (ATM2017), June 26-30, 2017, Seattle, WA.

[10] Homola, J., Mohlenbrink, C., Dao, Q., Claudatos, L., Martin, L., \& Mercer, J. (2017) UAS Technical Capability Level 2 Unmanned Aircraft System Traffic Management (UTM) Flight Demonstration: Description and Analysis. IEEE-DASCSeptember 17-21, 2017 St. Petersburg, FL.

[11] National Police Agency Emergency Disaster Security Headquarters of Japan, "Damage Statistics and Police Activities for 2011 Tohoku earthquake," 2018. URL: https://www.npa.go.jp/news/other/earthquake2011/pdf/higaijokyo.pdf [accessed 13 May 2018] (in Japanese)

[12] Emergency Response Office, Fire and Disaster Management Agency of Japan, "The 2016 Kumamoto Earthquake, Report No. 114," 2018. URL: http://www.fdma.go.jp/bn/4dcd38fac5307f09c2f45e0016c29a56c35a0501.pdf [accessed 13 May 2018] (in Japanese)

[13] Geospatial Information Authority of Japan, "Information on the 2016 Kumamoto Earthquake," URL: http://www.gsi.go.jp/B OUSAI/H27-kumamoto-earthquake-index.html [accessed 13 May 2018] (in Japanese)

[14] Geospatial Information Authority of Japan, “Information on the 2014 Hiroshima Landslide,” URL: http://www.gsi.go.jp/BO USAI/h26-0816heavyrain-index.html [accessed 13 May 2018] (in Japanese)

[15] Telecommunications Bureau, Ministry of Internal Affairs and Communications of Japan, "2011 White Paper Information and Communications in Japan," 2011. URL: http://www.soumu.go.jp/johotsusintokei/whitepaper/ja/h23/html/nc100000.html [accessed 13 May 2018] (in Japanese)

[16] Telecommunications Bureau, Ministry of Internal Affairs and Communications of Japan, "Response to the Kumamoto Earthquake 2016 by Telecommunications Carrier Companies," 2016. URL: http://www.soumu.go.jp/main_content/00043233 7.pdf [accessed 13 May 2018] (in Japanese)

[17] Shiro Takada, and Toshinobu Imanaka, "Function Interruption and Emergency Response of Power and Communication Systems during 2014 Hiroshima Land-slide Disaster," Memoirs of Construction Engineering Research Institute, Vol. 57, pp. 57-67, 2015. (in Japanese)

[18] Aeronautical Information Service Center, Japan Civil Aviation Bureau, "Aeronautical Information related to Kumamoto Earthquake,” 2018. URL: http://www.mlit.go.jp/common/001127985.pdf [accessed 13 May 2018] (in Japanese) 